\title{
The Development of Glomerular Capillary Tufts of the Bullfrog Kidney from a Straight Interstitial Vessel to an Anastomosed Capillary Network. A Scanning Electron Microscopic Study of Vascular Casts
}

\author{
Ichiro NAITO \\ Department of Anatomy (Prof. T. Murakami), Okayama University Medical School, and Shigei Medical \\ Research Institute (Prof. emer. S. SEno), Okayama, Japan
}

Received March 9, 1984

\begin{abstract}
Summary. Blood vascular tufts of immature glomeruli of the post-metamorphous bullfrog kidney were reproduced by a resin casting medium and observed by scanning electron microscopy. The simplest glomerular tufts consisted of a single straight vessel continuous with the afferent and efferent vessels. In the next stage, the single vessel dilated and bent to form a U-shaped loop; this loop sprouted free-ending protrusions. Subsequently a conglomerated network of anastomosing capillaries developed. The network became larger, and increased in number of capillaries. Even during these later stages, the capillaries possessed luminal protrusions with free endings. Small holes and narrow grooves representing endothelial intrusions into the capillary lumens were noted only rarely. The findings supported the in-growth concept, in that an interstitial vessel invaded the cleft of the S-shaped renal vesicle to form a glomerular capillary network. Secondly, the glomerular capillaries multiplied by sprouting daughter capillaries rather than by luminal splitting.
\end{abstract}

Recent scanning electron microscope studies of vascular casts of mesonephric kidneys in the post-metamorphous bullfrog and toad have demonstrated that the mature glomeruli of these amphibians consist of anastomosing capillaries (MORRIS and CAMPBELL, 1978; OhtAni and Naito, 1980). The structure is similar to that in human and other metanephric kidneys (Murakami, 1972, 1977; Unehira, 1981). Besides this, the postmetamorphous bullfrog mesonephric kidneys contain a number of small immature glomeruli showing a rather simple vascular pattern (OHTANI and NAITo, 1980). In this report, the vasculature of these immature glomeruli are analyzed by scanning electron microscopy of vascular casts and the development of the glomerular capillary tuft is discussed.

\section{MATERIALS AND METHODS}

Post-metamorphous and adult bullfrogs (Rana catesbeiana), weighing 200-300g each, were anesthetized by immersion in a solution containing $0.05 \%$ meta aminobenzoic acid 
ethylester methanesulfonate (MS222, Sankyo Co. Ltd., Tokyo). After decapitation and incision of the right cardiac atrium, the animals were perfused carefully and thoroughly through either aortic arch using a $0.7 \% \mathrm{NaCl}$ solution. This was followed by a commercially available, low viscosity resin casting medium (Mercox, Japan Vilien Ltd., Tokyo). The kidneys were then removed, digested in a hot $10 \% \mathrm{NaOH}$ solution, washed in running tap water, frozen in water, cut into suitable blocks, and dried in air. The vascular casts were coated with gold in an ion-coater (IB-3, Eiko Engineering Ltd., Mito) and observed under a scanning electron microscope (S-310, Hitachi, Tokyo). The acceleration voltage was $4 \mathrm{kV}$. Alternatively, unperfused bullfrog kidneys were directly cut into blocks, immersion-fixed with $10 \%$ formalin, embedded in paraffin, thin-sectioned, stained with hematoxylin-eosin, and observed under a light microscope.

\section{RESULTS}

Many small or immature glomeruli were seen by light microscopy in the ventro-medial margin of sectioned post-metamorphous bullfrog kidneys (Fig. 1). The smallest or most immature glomeruli were surrounded by the S-shaped renal vesicle, or primitive Bowman's capsule. Mature glomeruli were located preferentially in the medulla

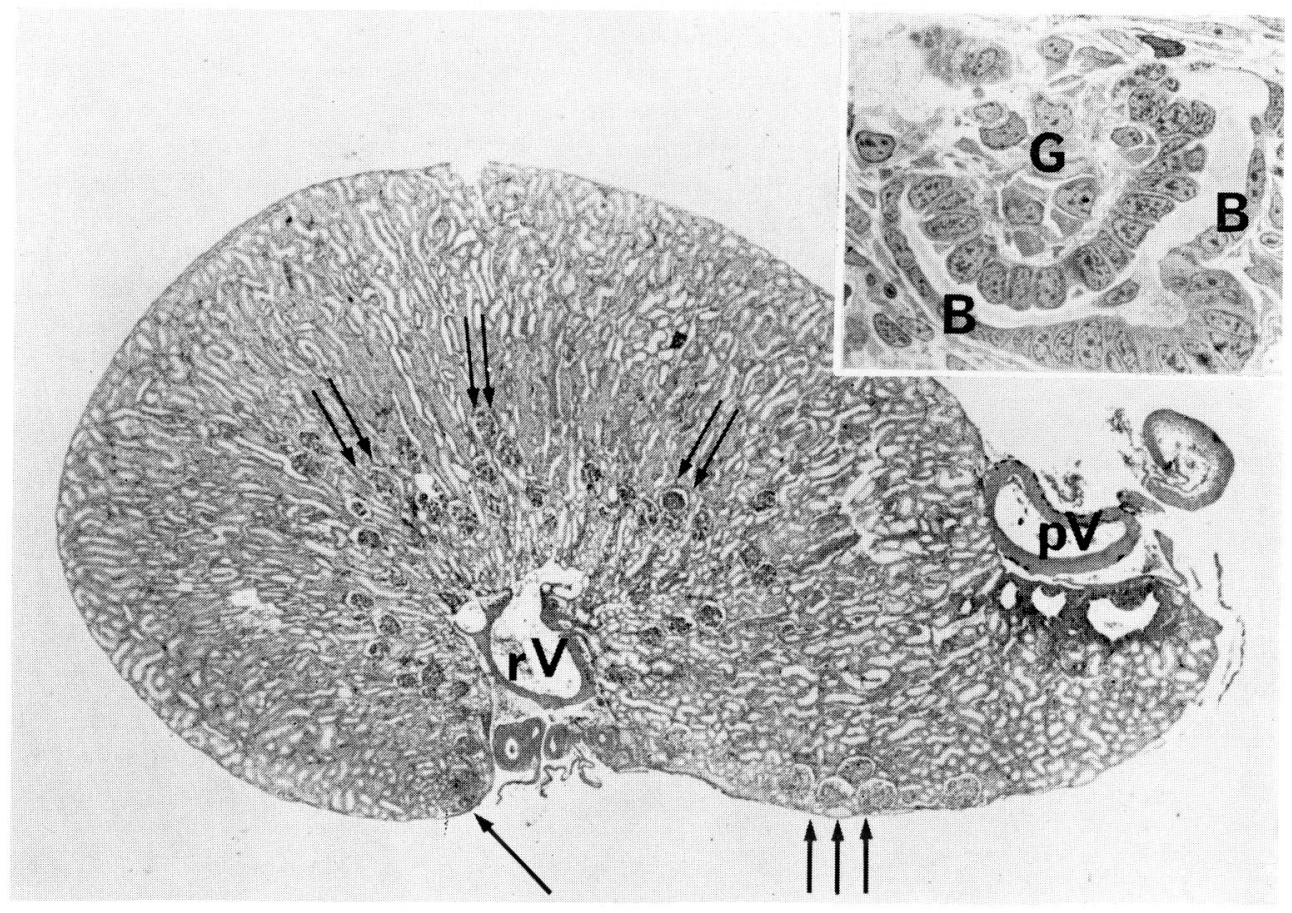

Fig. 1. Light micrograph of a transverse section from a post-metamorphous bullfrog kidney. Note small, or immature glomeruli in the ventro-medial margin (single arrow). Medium-sized, or mature, glomeruli (double arrows) are located in the medulla near the renal vein $(r V)$. The largest, or most-developed, glomeruli (triple arrows) can be observed beneath the ventrolateral surface. $p V$ portal vein. Hematoxylin-eosin stain. $\times 9$. Inset. Immature glomerulus from the ventro-medial margin. $B$ Bowman's capsule, $G$ glomerulus. $\quad \times 500$ 
close to the renal vein. The largest, or most mature, glomeruli were found internal to the ventro-lateral surface (Fig. 1).

Careful and thorough injection of the Mercox resin medium resulted in full castings of the entire vascular beds of both kidneys with few leaks. These samples presented somewhat expanded vascular lumens, but enabled detailed scanning electron microscopic analyses of vascular connections and distributions, including those of the immature glomeruli of the ventro-medial margin.

The immature glomeruli were characterized by simple vascularizations (Fig. 2). Like mature glomeruli (OHTANI and Naito, 1980), they received afferent vessels from the renal artery. The efferent vessels were continuous with the peritubular sinusoidal capillaries. Casts of afferent and efferent vessels of the immature glomeruli were impressed with circular ridges due to vascular contractions. Such ridges were not readily visible on the glomerular capillaries.

Capillary tuft structures of the immature glomeruli varied widely. They were arbitrarily classified into several groups or stages according to their vascular development. The simplest, or first-stage immature glomerular vascular tuft was a rather straight vessel (Fig. 2b, 3). This vessel was either slender or slightly dilated. In the former case, it was difficult to determine the true glomerular capillary segment from afferent and efferent vessels.

The second-stage glomerular tuft presented a marked dilation and bending or twisting, thus forming a U-shaped loop clearly discernible from afferent and efferent vessels (Fig. 4a). Occasionally, the dilated, U-shaped loops presented small, rounded or elongated protrusions, whose terminal edges ended freely (Fig. 4b). These protrusions could occur along the entire surfaces of the loop.

The third-stage glomerular vascular tuft was reproduced as a few looped capillaries of thick calibers (Fig. 5). These looped vessels bridged afferent and efferent vessels. Occasionally, however, some constrictions and subdivisions were present at various segments. The constrictions were funnel-shaped; the subdivided capillaries could be as thick as their parent looped vessels. In addition, the looped vessels formed frequent anastomoses between themselves and small protrusions with free endings. The anastomoses were usually thin, and encircled by clearly delineated, ring-like striations. The shapes of the protrusions were similar to those observed in second-stage tufts (Fig. 4). Furthermore, certain segments of the looped vessels occasionally contained marked surface-defects which were characterized by deeply pitted small holes and narrow grooves.

The fourth-stage glomerular vascular tufts presented primitive conglomerated capillary networks (Fig. 6). At this stage the vascular and urinary poles were clearly differentiated. The capillaries of this network always contained anastomoses or interconnections among themselves. As the tufts developed further, the conglomerated networks became larger and contained more capillaries and anastomoses (Fig. 7, 8, 9). Even in these later developments-including the fourth-stage-constrictions and small, free ending protrusions, such as observed in the second and third-stages, were noted occasionally, though their locations were restricted to or near the vascular pole (Fig. 8). Surface defects seen in more immature stages were observed very infrequently near the vascular pole (Fig. 9). Only rarely in the later stages did these anomalies occur at the urinary pole. Glomerular capillary thickness varied in individual tufts. Overwhelmingly, the glomerular capillaries were of equal or greater thickness than the afferent and efferent vessels. In a number of glomeruli, however, slender capillaries blended and intermingled with the usual, thick capillaries. When present, these 
slender capillaries only occurred as clusters near the vascular pole (Fig. 7) or as isolated anastomosing channels between thick capillaries. These interconnecting channels were not seen near the urinary poles.

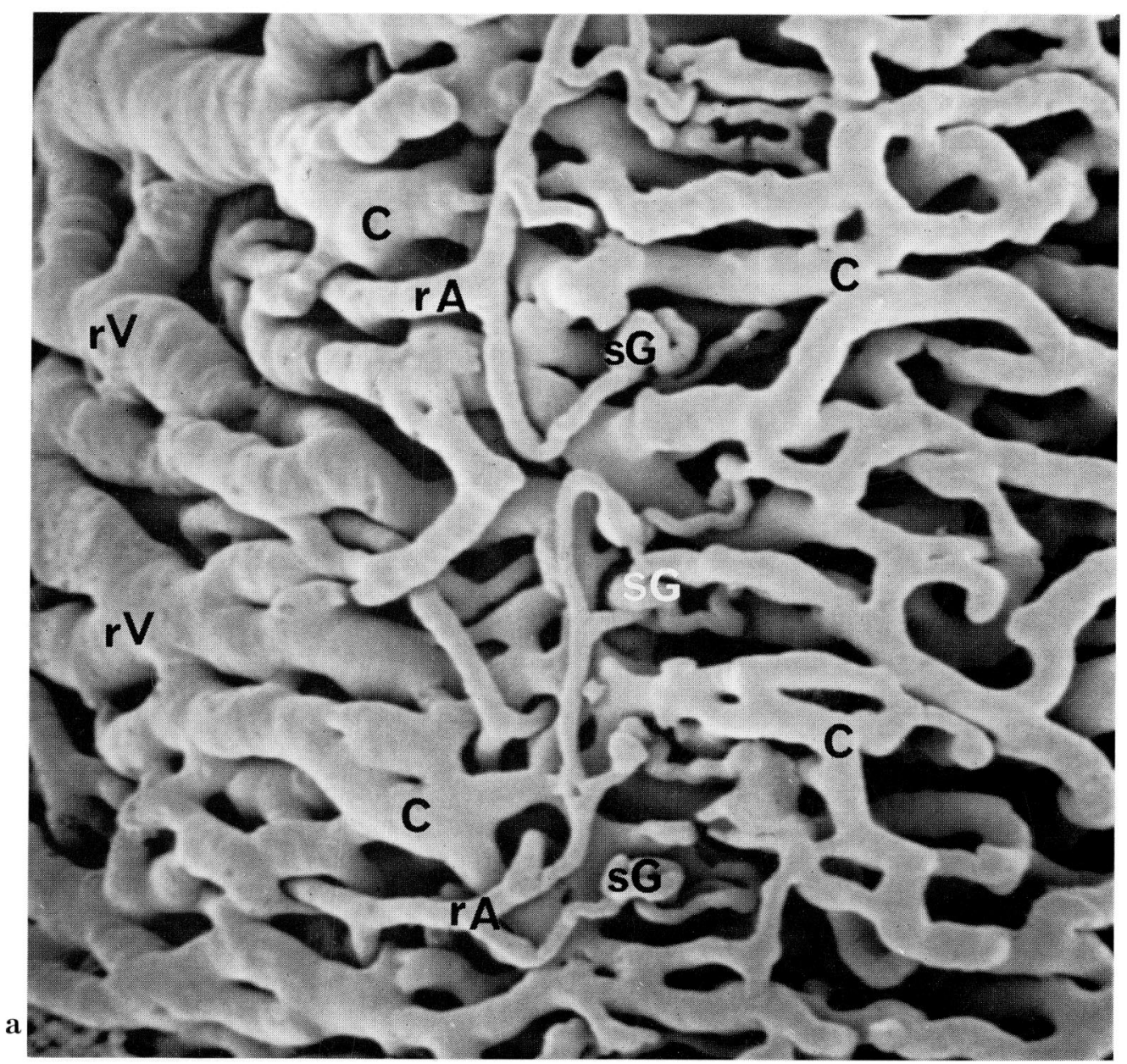

Fig. 2. a-c. Scanning electron micrographs of casted vasculature of the ventro-medial margin (a), and immature (b) and mature glomeruli (c) of post-metamorphous bullfrog kidneys. a. Note many small glomeruli $(s G)$ with simple vascularization beneath the renal ventro-medial surface. These glomeruli are continuous with branches of the renal artery $(r A)$, and the peritubular sinusoidal capillaries $(C)$. These peritubular capillaries arise from portal vein branches, and drain into renal vein branches $(r V)$ (see Ohtani and Naito, 1980). $\times 150$. b. An immature glomerulus from the ventro-medial margin. Note that the lower straight vessel arises from a terminal branch of the renal artery $(r A)$ and drains into the peritubular capillary. The middle segment $(M)$ of this vessel corresponds to a glomerulus, though its identification is difficult as it is of similar thickness to the afferent (A) and efferent ( $E$ ) vessels. The upper conglomerated tuft $(G)$ of thickened capillaries is in a later stage of development. $\times 1,200$. c. Note mature glomeruli $(m G)$ consisting of many anastomosing capillaries. A afferent vessel, $C$ peritubular capillaries, $E$ efferent vessel, $r A$ renal artery branch. Triple arrows: vascular contractions. $\times 300$ 

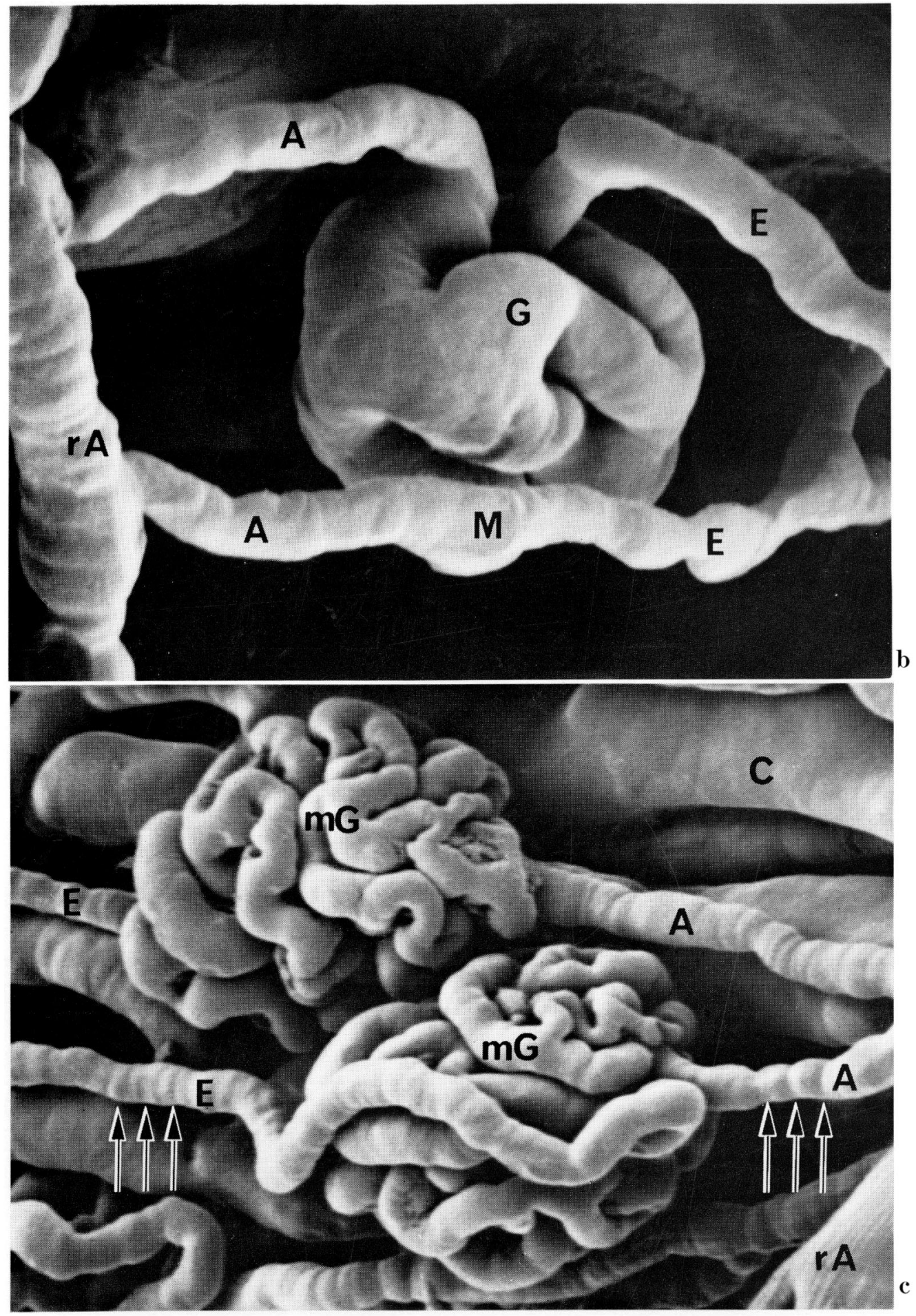

Fig. 2. a-c. Legend on the opposite page. 

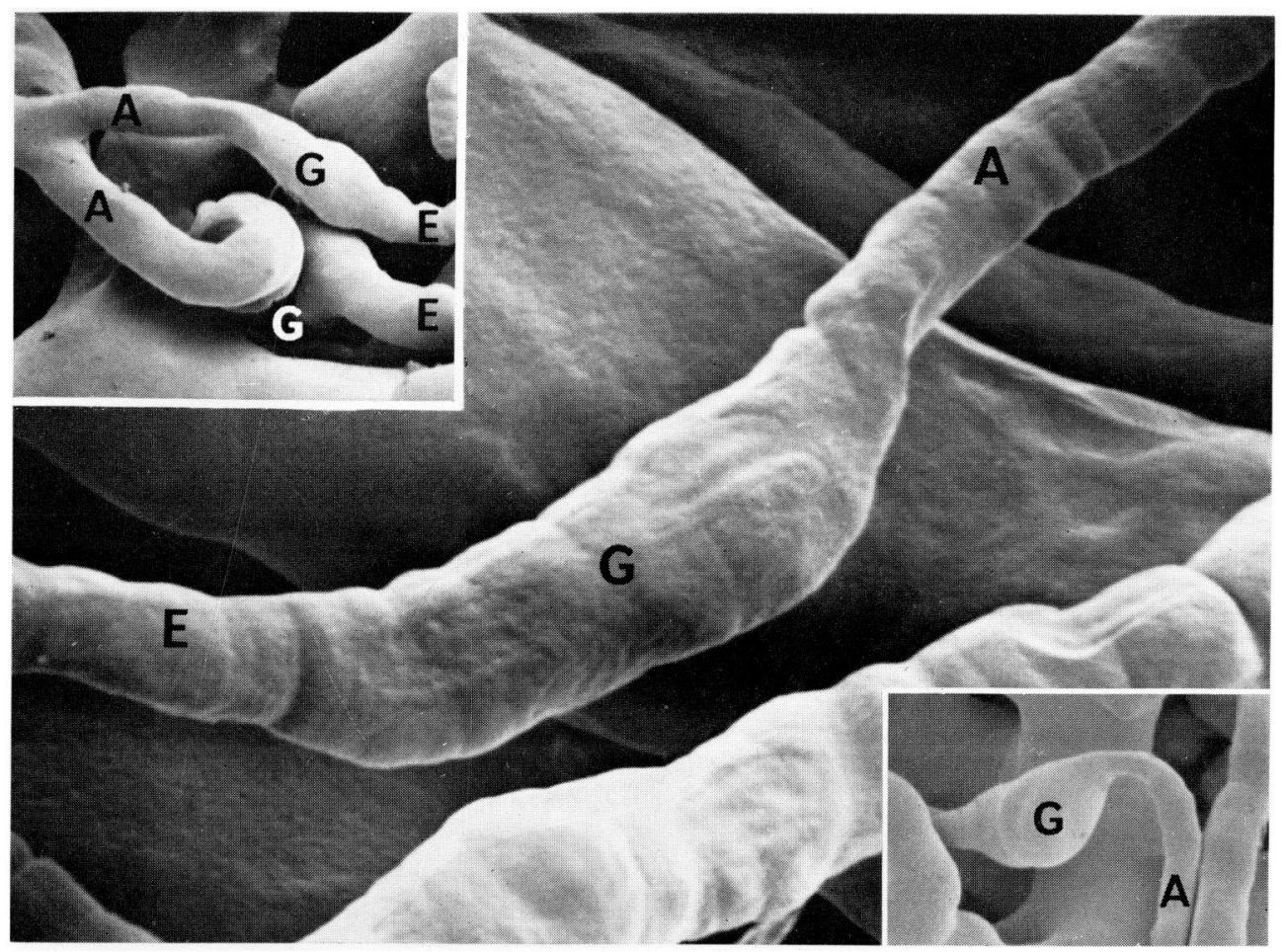

Fig. 3. SEM of primitive glomerular capillary tufts. The primitive glomerular capillary tuft consisted of a single dilated capillary $(G)$ is easily discernible from afferent $(A)$ and efferent $(E)$ vessels. $\times 1,300$. Insets. Conformational variations of primitive, dilated glomerular capillaries $(G)$ intercalated between afferent $(A)$ and efferent $(E)$ vessels are shown. $\quad \times 400$

\section{DISCUSSION}

The mesonephric kidney of the post-metamorphous bullfrog contains a wide variety of glomeruli in various stages of development. Analysis of casted samples clearly points to a developmental sequence starting with a simple single vessel, which coils, anastomoses and finally forms a conglomerated capillary network. These findings coincide with those obtained in the newborn rat metanephros, using similar techniques (KAZIMIERCZAK, 1978, 1980).

The location of the early development of the meta- and meso-nephric glomerular capillary has been established as the lower cleft of the S-shaped renal vesicle (GRAY, 1936; Kissane, 1974). However, two main theories as to its origin, whether in-growth and in-situ, are still in contention. The in-growth theory posits that the glomerular capillary originates directly from an interstitial vessel (PotTER, 1965; OsathanondH and Potter, 1966; Ishi, 1970; Kazimierczak, 1971; Gattone et al., 1979). The in-situ theory claims that the glomerular capillary develops in the cleft and later makes

Fig. 4. a and b. SEM of U-shaped, second-stage glomerular capillary tufts (G). a. Afferent (A) and efferent $(E)$ vessels. $\times 1,800$. Inset. Another typical U-shaped glomerular capillary loop $(G) . \times 700$. b. A U-shaped glomerular capillary $(G)$ sprouting protrusions with free endings (arrowheads). $\times 1,500$. Inset. Another similar, U-shaped capillary $\operatorname{loop}(G) . \quad \times 900$ 

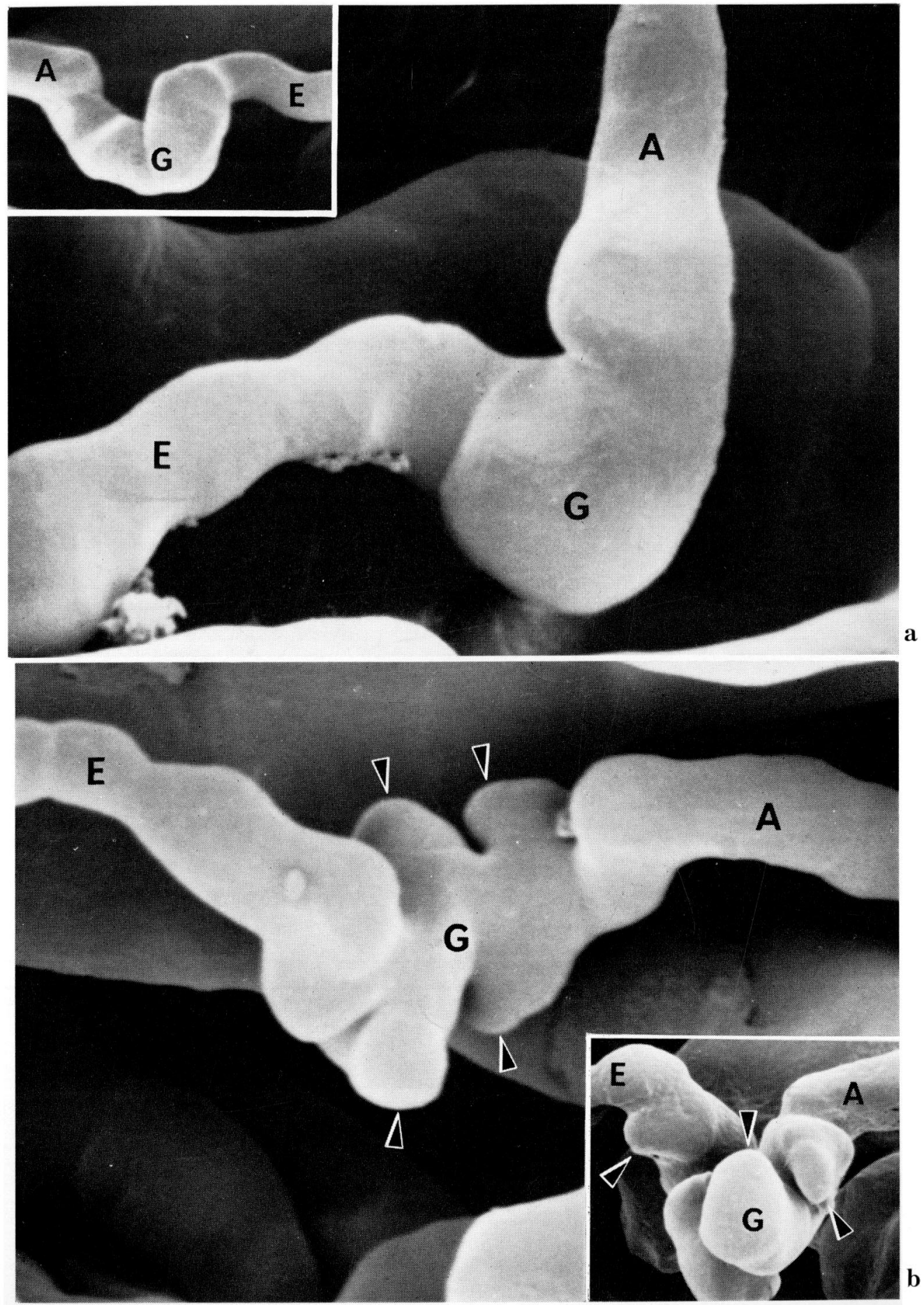

Fig. 4. a and b. Legend on the opposite page. 


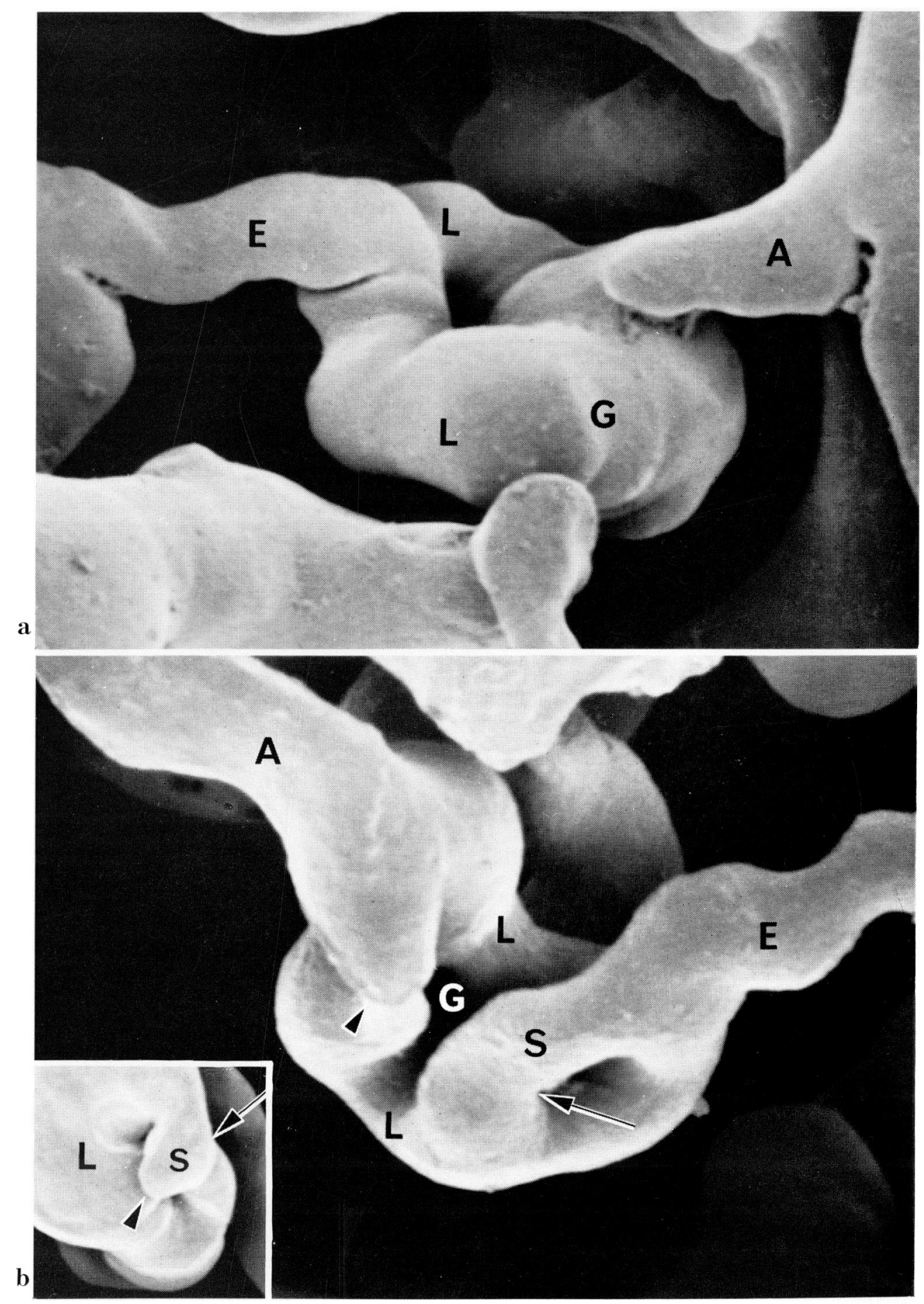

Fig. 5. a-e. Legend on the page 450 . 

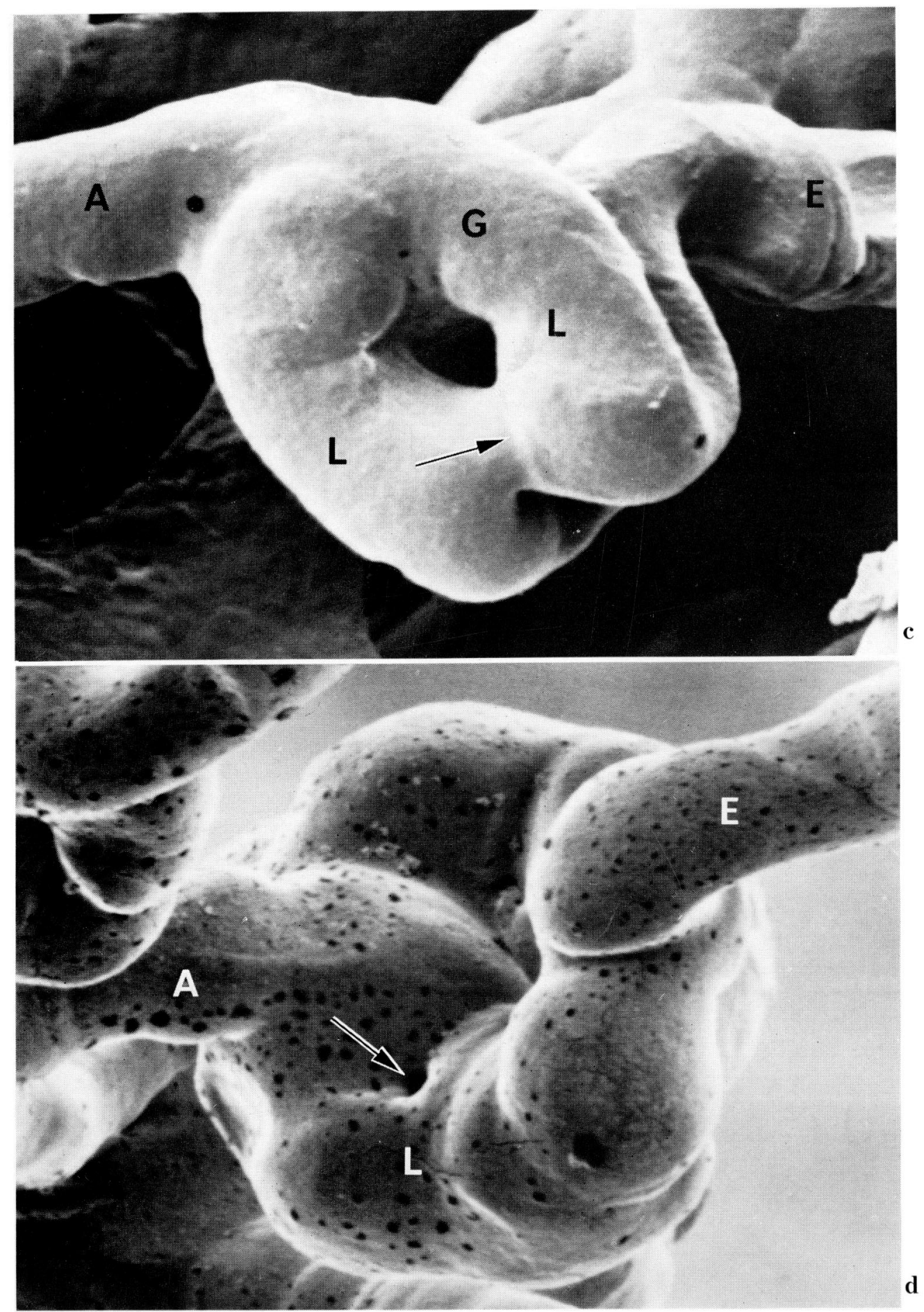

Fig. 5. a-e. Legend on the page 450 . 


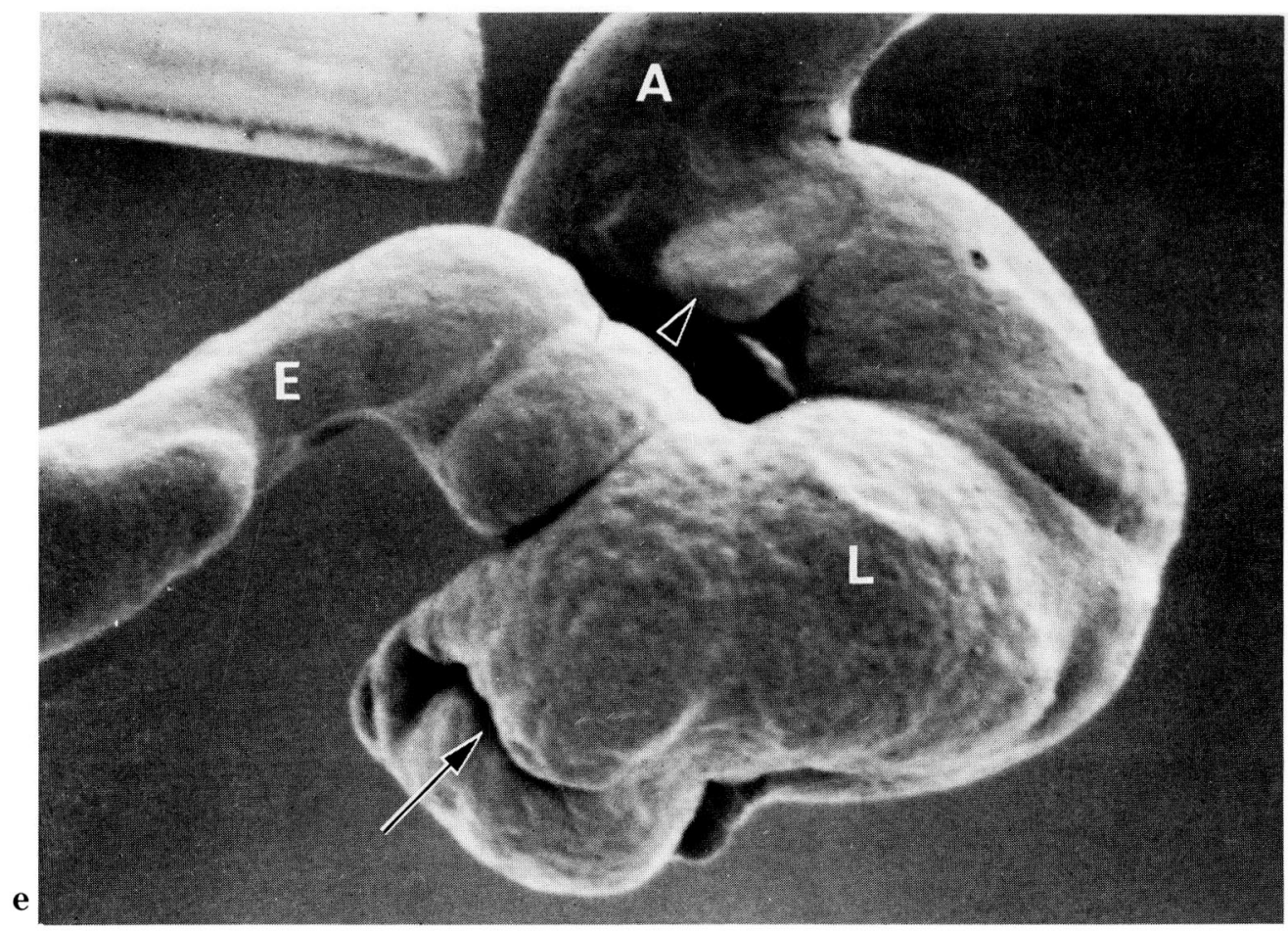

Fig. 5. a-e. Third-stage glomerular capillary tufts. a. A typical, uncomplicated example of this stage consisting of a few looped capillaries $(L)$ comprising the glomerulus $(G) . \quad \times 1,300$. b. A tuft of looped capillaries $(L)$ presenting a marked constriction (arrow). The subdivided capillary in this case is as thick as the parent. $\times 2,100$. Inset. A capillary subdivision (arrow) markedly thinner than the parent $(L)$. The subdivided capillary sprouts a small protrusion with a free ending (arrowhead). $\times 950$. c. Anastomosis or interconnection of thirdstage looped capillaries $(L)$. Note a marked ring-like striation impregnated on the anastomosis (arrow). $\times 1,800$. e and d. Surface-defects such as small holes (d; arrow) and narrow grooves (e; arrow) are seen rarely in these capillaries $(L)$. Arrowhead (e): an external protrusion of glomerular capillary lumen. $\mathrm{d}: \times 1,700$, e: $\times 1,800$

connections with neighboring interstitial vessels (SUZUKI, 1959; VerNIER and BirchANDERSEn, 1962). Examination of the metanephric kidney revealed that the glomerular capillary begins as a straight vessel continuous with interstitial afferent and efferent vessels; in the second stage the capillary dilates to form a U-shaped loop. This characteristic dilation and loop formation of the interstitial vessel supports the ingrowth theory.

As the glomerulus developed further, more capillaries were contained in the glomerular tuft. New capillaries were formed continuously in the developing glomerulus. Light microscopic investigations of India ink-injected and microdissected human embryo metanephric kidney glomeruli demonstrated that the enfaced (upper and lower) luminal surfaces of dilated vessels contact each other, fuse, and produce fenestrations

Fig. 6. A primitive conglomerated glomerular capillary network of the fourth stage. The vascular $(v P)$ and urinary $(u P)$ poles are well-differentiated. $\times 1,200$

Fig. 7. A fifth-stage developing glomerulus. Clustered thin capillaries ( $S$ ) bridge between the usual, thick ones (L). A protrusion (arrowhead) can be seen in the vascular pole. $\times 950$. Inset. An isolated thin capllary $(S)$ interconnecting the usual, thick ones $(L) . \quad \times 800$ 


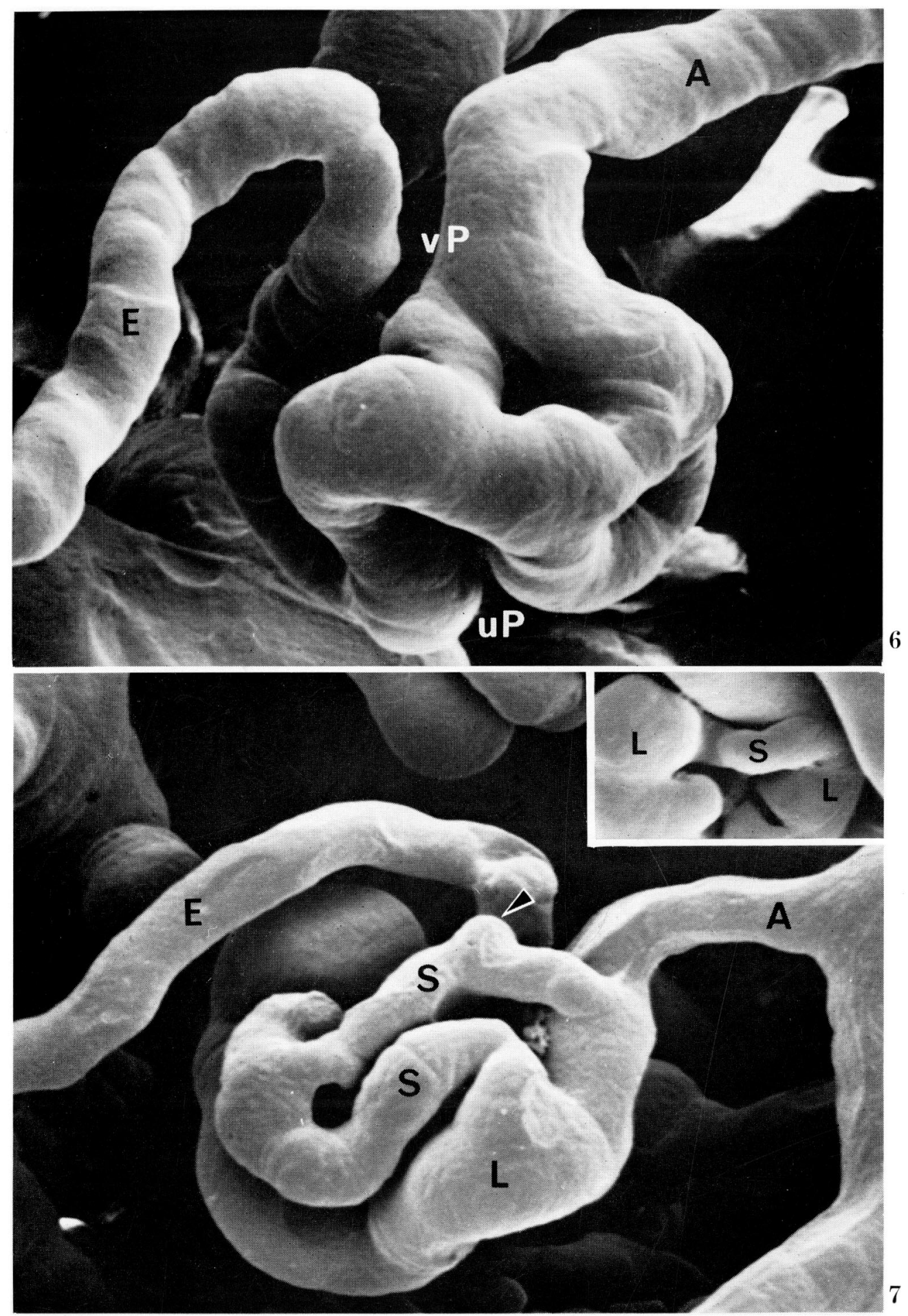

Fig. 6 and 7 . Legends on the opposite page. 


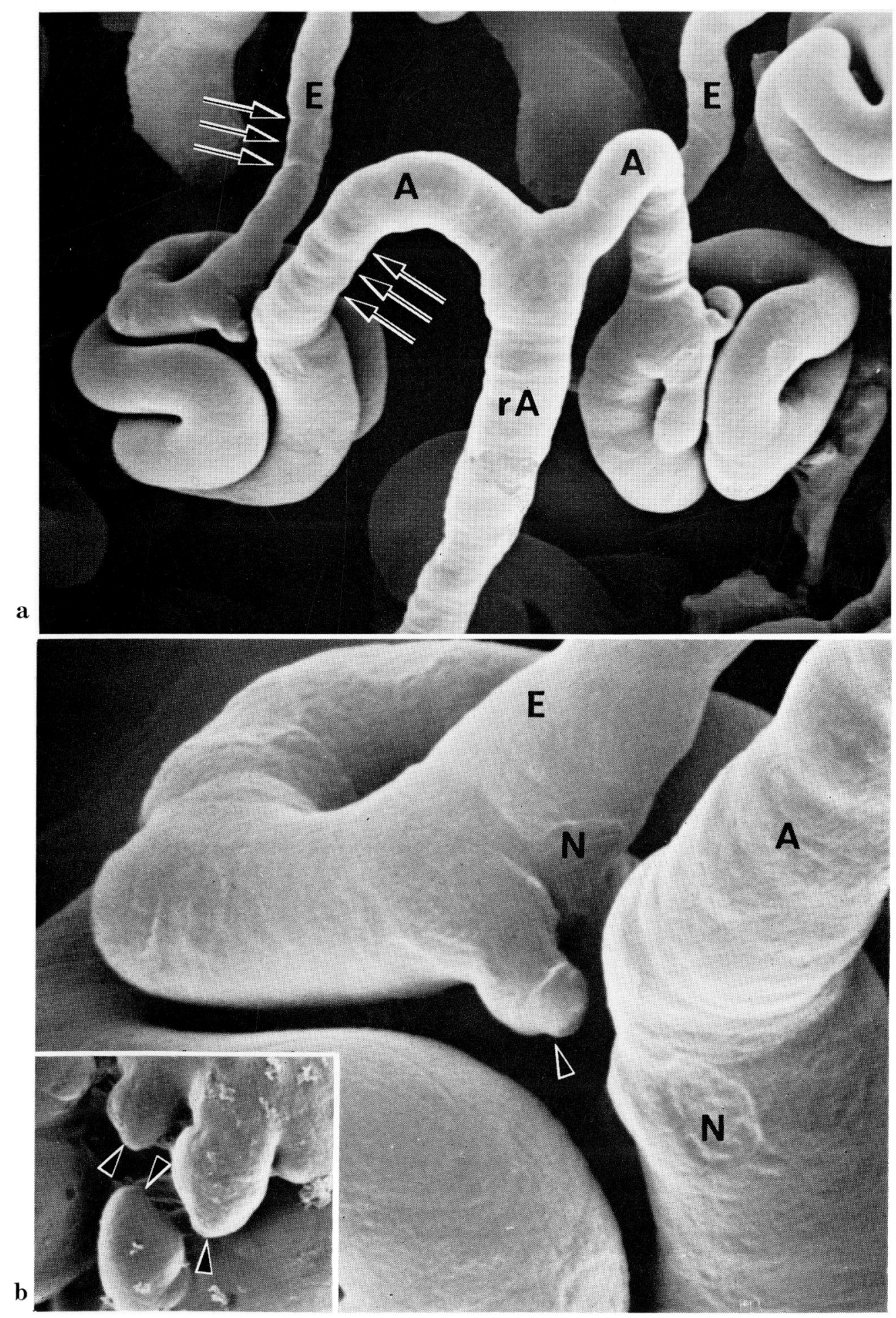

Fig. 8. a-c. Legend on the opposite page. 


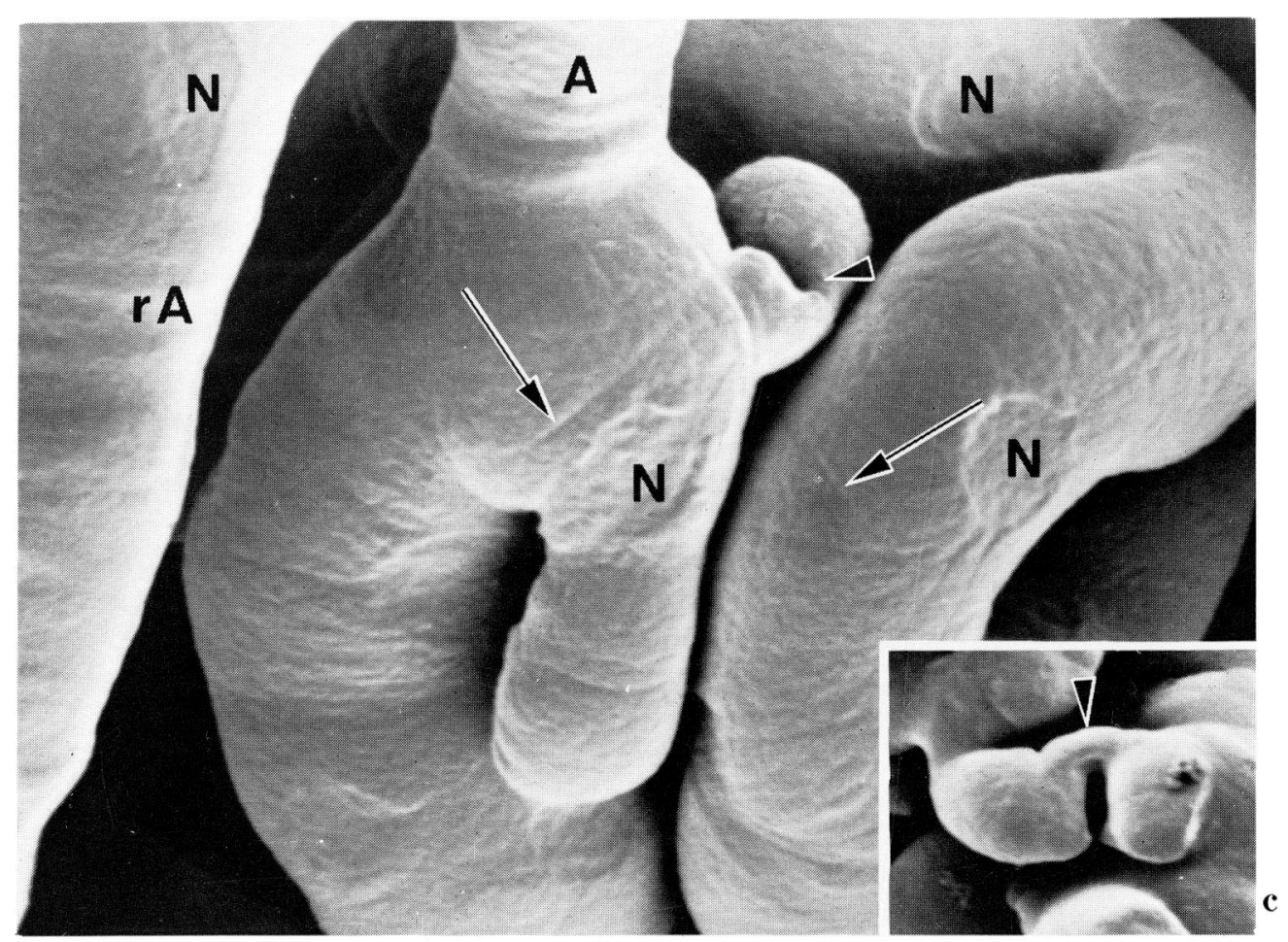

Fig. 8. a-c. Nearly mature glomeruli. a. Two glomeruli branching from the same renal artery branches $(r A)$ present vascular contractions (triple arrows) on both afferent $(A)$ and offerent $(E)$ vessels. $\times 450$ b. A highly magnified segment of the left glomerulus demonstrating a small protrusion (arrowhead) in the vascular pole. The impression of an endothelial nucleus is also seen $(N)$. $\times 1,700$. Inset. The protrusions (arrowheads) also occured in groups. $\times 2,300$. c. A highly magnified segment of the right glomerulus highlights a marked constriction (arrowhead) of a capillary in the vascular pole. Endothelial nuclei $(N)$ and cell boundaries (arrows) can be noted. $\times 1,200$. Inset. Another case of marked constriction (arrowhead). $\times 950$

or divide into several capillaries (Osathanondh and Potter, 1966). Kazimierczak (1971) prepared reconstruction models based on light microscopic analyses of sectioned newborn pig kidneys. Here, endothelial cells were found to protrude into capillary lumens and form septa. This concept implies that the lumens of such a double capillary are continuous at both ends of the septum. However, the present study of fully casted samples demonstrated small, rounded and elongated capillary protrusions throughout the glomerular development. These protrusions with free endings represented luminal discontinuities. Furthermore, developing glomerular capillaries occasionally exhibited marked constrictions, suggestive of fusion sites of these protrusions. Thin anastomoses and interconnections encircled by ring-like striations also may have represented such fusion sites. Surface defects, such as small holes or narrow grooves, which may represent endothelial expansions or septa within the capillary lumens, were noted only rarely. These structures suggested that developing glomerular capillaries mainly sprout daughter capillaries from their external surfaces.

Glomerular capillary multiplication by surface sprouting or angiogenesis has been reported in mature glomeruli of the monkey kidney (UneHira, 1981). Such a mechanism also occurs in other tissues such as the developing neurohypophysis of the mouse 

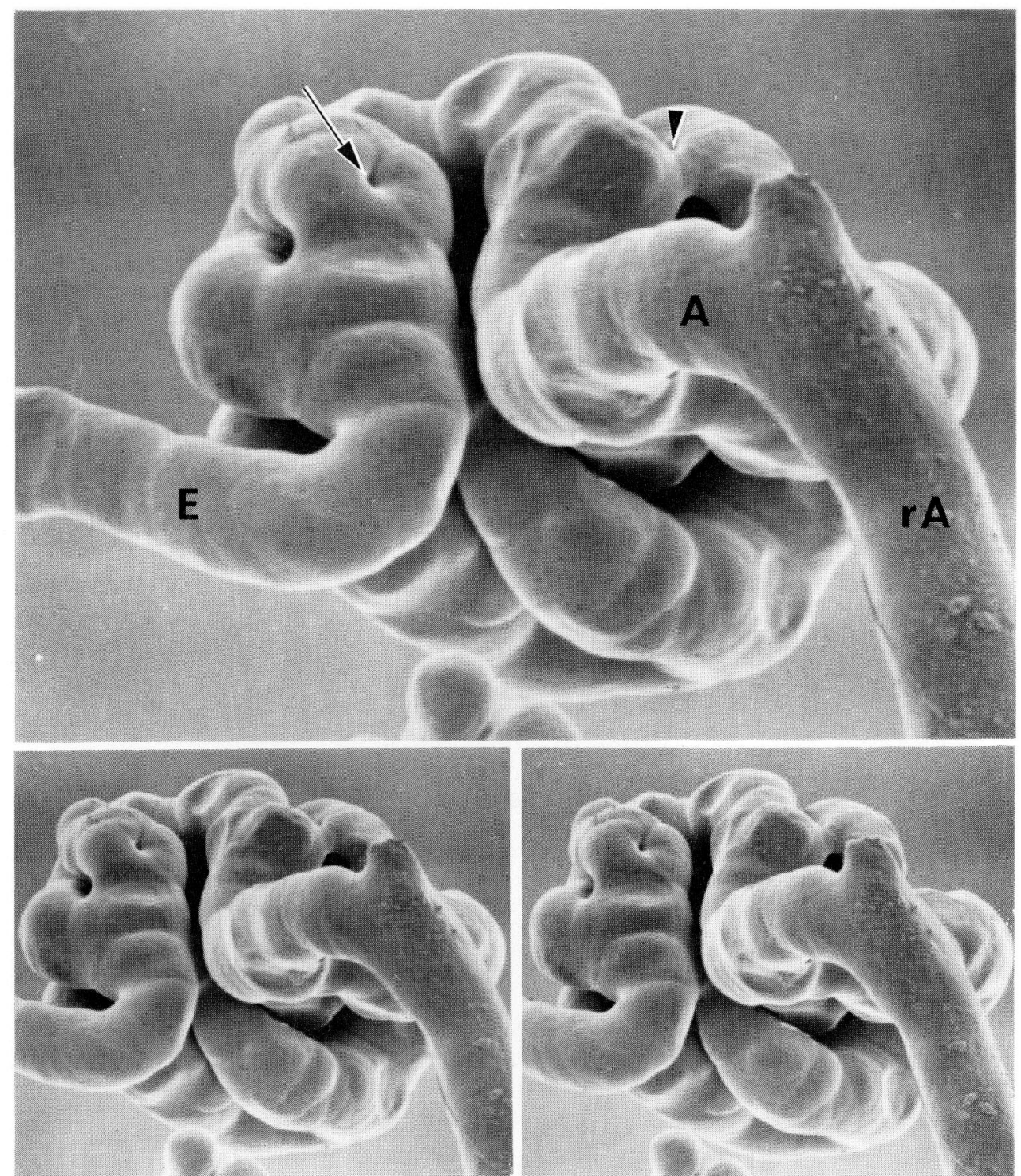

Fig. 9. A glomerular blood vascular tuft, in a final stage of development. Note the small hole (surface defect) (arrow) and thin anastomoses (arrowhead) near the vascular pole. $\times 1,200$. Insets. Stereo-pair of the same glomerulus. $\times 700$

(Eurenius, 1977), experimentally implanted tumors (Ausprunk, 1979), and the inflamed rabbit cornea (Yamagami, 1970; McCRACKen et al., 1979).

ZLÁBEK (1973) observed, under light microscopy, in Indian ink-injected sectioned adult rat kidneys, thin capillaries intercalated between the usual, thick capillaries of glomeruli. The thin capillaries were regarded as the preferential channels for blood serum. Similar thin vessels were noted near the vascular poles of the monkey mature glomeruli (UNEHIRA, 1981). Herein, such vessels were noted frequently even in immature, developing glomeruli. Based upon current observations, these thin capillaries 
must be considered newly formed ones, which, in time, develop into the usual, thick capillaries. The location of such protrusions and other structures (constrictions, small holes, and narrow grooves) suggests that new capillaries are preferentially formed near the vascular pole. Thus, the mesangium, macula densa, or other tissue elements such as Goormaghtigh's cells may be implicated in glomerular angiogenesis.

Previous scanning electron microscope investigations of casted samples have shown that the mature kidney glomerular capillary networks of the post-metamorphous bullfrog, like those of man, and the monkey, rat and other animals (MURAKAmI, 1971, 1972, 1976; UNEHIRA, 1981), occasionally present lobulations which are independently (with few anastomoses or interconnections) intercalated between afferent and efferent vessels (OHTANi and Naito, 1980). The present study suggests that these lobulations are differentiated during an early stage of glomerular development. Possibly, failure of anastomoses between third-stage looped capillaries leads to the formation of independent lobules.

Acknowledgments. The author is grateful to Dr. Hiroshi SHigeI, Chairman of the Board, Shigei Medical Research Institute, for his keen and continuous support.

\section{REFERENCES}

Ausprunk, D. H.: Tumor angiogenesis. In: (ed. by) J. C. Houck: Chemical messengers of the inflamatory process. Elsevier/North-Holland Biomedical Press, Amsterdam, 1979 (p. 317-351).

Eurenius, L.: An electron microscope study of the differentiating capillaries of the mouse neurohypophysis. Anat. Embryol 152: 89-108 (1977).

Gattone II, V. H., M. L. Johnson and D. E. Morse: A scanning electron microscopic study of capillary growth into the developing canine renal glomerulus. J. submicrosc. cytol. 11: 365-368 (1979).

Gray, P.: The development of the amphibian kidney. Part III. The post-metamorphic development of the kidney, and the development of the vasa efferentia and seminal vesicles in Rana temporaria. Quart. J. microsc. Sci. 78: 445-473 (1936).

Ishii, Y.: An ultrastructural study of the intrauterine development of rabbit metanephric glomeruli. Sapporo Med. J. 37: 53-78 (1970).

Kazimierczak, J.: Development of the renal corpuscle and the juxta-glomerular apparatus: A light and electron microscopic study. Acta pathol. microbiol. scand. Sect. A 218: 1-115 (1971).

- Topography and structure in developing cortex of rat kidney. Anat. Embryol. 153: 213226 (1978).

- A study by scanning (SEM) and transmission (TEM) electron microscopy of the glomerular capillaries in developing rat kidney. Cell Tiss. Res. 212: 241-255 (1980).

Kissane, J. M.: Development of the kidney. In: (ed. by) R. H. Heptinstall: Pathology of the kidney. Vol. I. Little Brown, Boston, 1974 (p. 51-68).

McCraken, J. S., P. C. Burger and G. K. Klintworth : Morphologic observations on experimental corneal vascularization in the rat. Lab. Invest. 41: 519-530 (1979).

Morris, J. L. and G. Campbell : Renal vascular anatomy of the toad (Bufo marinus). Cell Tiss. Res. 189: 501-514 (1978).

Murakami, T.: Application of the scanning electron microscope to the study of the fine distribution of the blood vessels. Arch. histol. jap. 32: 445-454 (1971).

-: Vascular arrangement of the rat renal glomerulus: A scanning electron microscope study of corrosion casts. Arch. histol. jap. 34: 87-107 (1972). 
Murakami, T.: Double afferent arteriole of the rat renal glomerulus as studied by the injection replica scanning electron microscope method. Arch. histol. jap. 39: 327-332 (1976).

- : Methyl methacrylate injection replica method. In: (ed. by) A. M. Hayat: Principles and techniques of scanning electron microscopy. Vol. 6. Van Nostrand Reinhold Co., New York, 1977 (p. 159-169).

Ohtani, 0. and I. Naito: Renal microcirculation of the bullfrog, Rana catesbeiana: A scanning electron microscope study of vascular casts. Arch. histol. jap. 43: 319-330 (1980).

Osathanondh, V. and E. L. Potter: Development of human kidney as shown by microdissection: V. Development of vascular pattern of glomerulus' Arch. Pathol. 82: 403-411 (1966).

Potter, E. L.: Development of the human glomerulus. Arch. Pathol. 80: 241-255 (1965).

Suzuki, Y.: An electron microscopy of the renal differentiation: II. Glomerulus. Keio J. Med. 8: 129-142 (1959).

Unehira, M.: Blood vascular architecture of the rhesus monkey kidney glomerulus. A scanning electron microscope study of corrosion casts. (In Japanese). Okayama Igakkai Zasshi 93: 951961 (1981).

Vernier, R. L. and A. Birch-Andersen: Studies of the human fetal kidney: I. Development of the glomerulus. J. Pediatr. 60: 754-768 (1962).

Yamagami, I.: Electron microscopic study on the cornea: I. The mechanism of experimental new vessel formation. Jap. J. Ophthalmol. 14: 41-58 (1970).

Zlábek, K.: Über düne interkapillare Anastomosen im Nierenglomerulus der Ratte. Acta anat. 85: 175-189 (1973).

内藤 一 郎

テ701-02 岡山市山田2117

重井医学研究所

超微形態部門
Dr. Ichiro Naito

Division of Ultrastructure Research Shigei Medical Research Institute 2117 Yamada, Okayama

701-02 Japan 